\title{
Are disease-related pulmonary perfusion abnormalities detectable in COVID-19 patients? Suspicious findings in a lung perfusion SPECT performed for ruling out classical pulmonary embolism
}

\author{
Roberto Sciagrà ${ }^{1}$ (D) Federica Rubino ${ }^{1} \cdot$ Danilo Malandrino $^{2} \cdot$ Nicoletta Bernardeschi $^{1} \cdot$ Alberto Moggi Pignone $^{3}$. \\ Andrea Berni ${ }^{2}$
}

Received: 29 April 2020 / Accepted: 12 May 2020 / Published online: 26 May 2020

(C) Springer-Verlag GmbH Germany, part of Springer Nature 2020

$\mathrm{PET} / \mathrm{CT}$ identifies FDG uptake, but presently there is no role for Nuclear Medicine in COVID-19 [1, 2]. However, thrombophilia is reported, and pulmonary emboli described [3-5]. In an 85-year-old man with dilated cardiomyopathy referred to the hospital because of dyspnea and cough, CT revealed bilateral pleural effusion with lower lobe ground glass opacities, but nasopharyngeal swab was negative for COVID-19, and hemoptysis plus persistence of severe hypoxemia with hypocapnia raised the suspicion

This article is part of the Topical Collection on Infection and inflammation.

Roberto Sciagrà

roberto.sciagra@unifi.it

Nuclear Medicine Unit, Department of Experimental and Clinical Biomedical Sciences, University of Florence, Careggi University Hospital, Florence, Italy

2 Internal Medicine 3, Department of Experimental and Clinical Medicine, University of Florence, Careggi University Hospital, Florence, Italy

3 Internal Medicine 4, Department of Experimental and Clinical Medicine, University of Florence, Careggi University Hospital, Florence, Italy of pulmonary embolism. Owing to elevated creatinine level, pulmonary perfusion SPECT was preferred, and initially reported as abnormal, but not diagnostic of acute embolism, because of uptake defects mainly coinciding with parenchymal anomalies. Subsequently, a second swab revealed infection by SARS-CoV-2. The patient was transferred to a COVID Unit, developed respiratory failure and fever $\left(38.5^{\circ}\right)$, and died 3 days later; last D-dimer was $1299 \mathrm{ng} / \mathrm{mL}$ and LDH $350 \mathrm{U} / \mathrm{L}$. The lung scan was then reviewed after fusion with last CT. Figures 1 and 2 show the presence in the perfusion SPECT images (left panel, upper row: transaxial and coronal slices; lower row: sagittal slice and three-dimensional rendering) of small peripheral uptake defects (white arrows and arrowhead). In the corresponding $\mathrm{CT}$ images (right panel: same disposition, scout image in the lower right corner), the red arrows point to the parenchymal areas corresponding to the perfusion defects, which appear normally ventilated. These findings suggest that lung perfusion SPECT could identify perfusion abnormalities in early phase of COVID-19. Further studies are desirable to establish whether this could be helpful for these patients. 


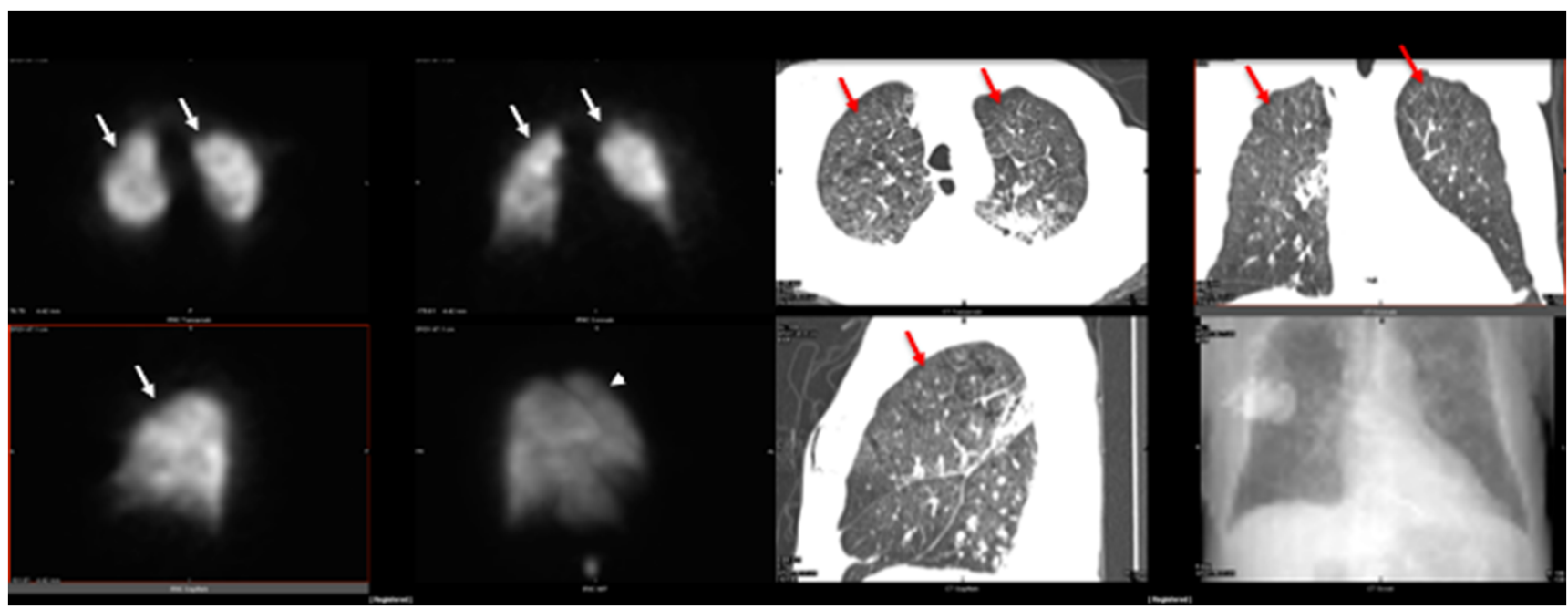

Fig. 1 Left panel: perfusion SPECT images, transaxial and coronal slices in the upper row, sagittal slice and three-dimensional rendering in the lower row. Small peripheral uptake defects are present (white arrows and arrowhead). Right panel: CT images, same slice disposition, plus scout image (lower right corner). The red arrows point to the parenchymal areas corresponding to the perfusion defects

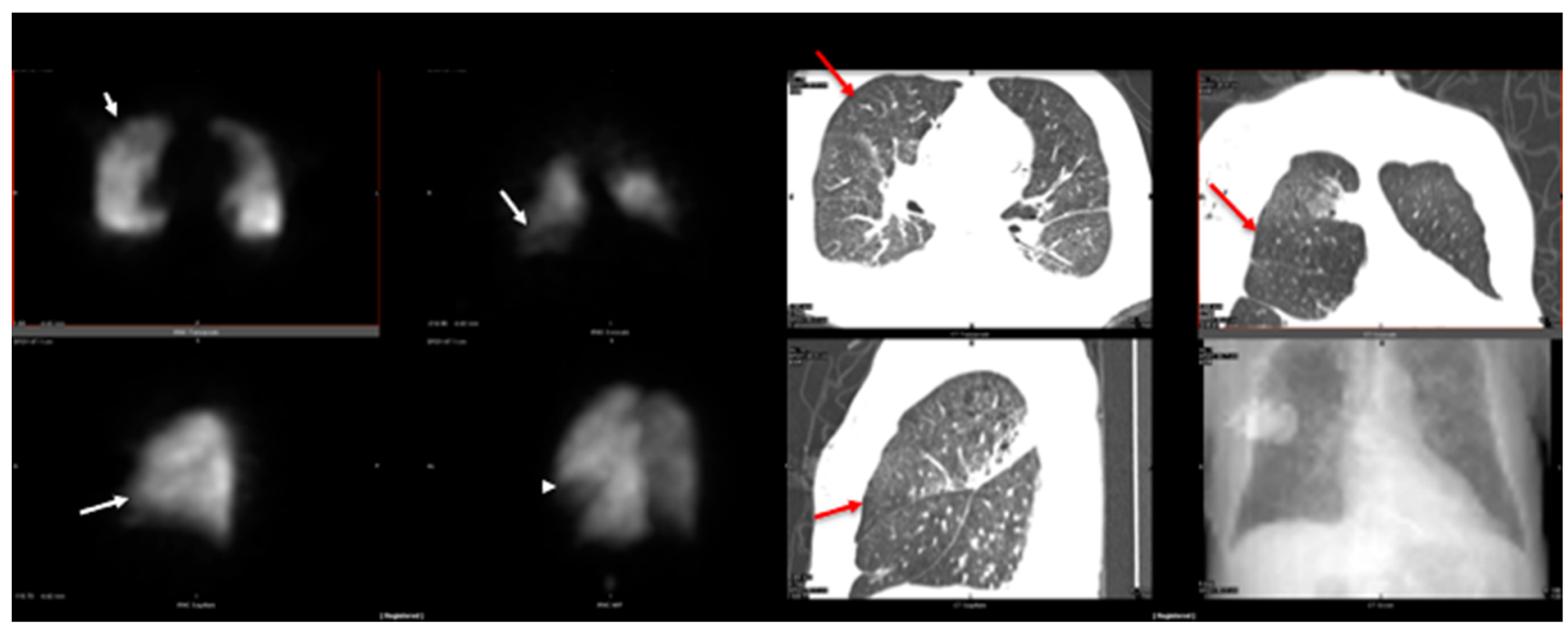

Fig. 2 Same image disposition as in Fig. 1, showing similar findings in more basal fields

\section{Compliance with ethical standards}

Conflict of interest The authors declare that they have no conflict of interest.

Ethical approval All procedures performed in studies involving human participants were in accordance with the ethical standards of the institutional and/or national research committee and with the 1964 Helsinki declaration and its later amendments or comparable ethical standards.

Informed consent According to our current Institutional procedure, the patient signature on the Exam Authorization Form includes the consent to the use of anonymized data for research purposes.

\section{References}

1. Qin C, Liu F, Yen TC, Lan X. F-FDG PET/CT findings of COVID19: a series of four highly suspected cases. Eur J Nucl Med Mol Imaging. 2020;47:1281-6.

2. Guedj E, Verger A, Cammilleri S. PET imaging of COVID-19: the target and the number [published online ahead of print, 2020 Apr 17]. Eur J Nucl Med Mol Imaging. 2020:1-2. https://doi.org/ 10.1007/s00259-020-04820-z.

3. Tang N, Li D, Wang X, Sun Z. Abnormal coagulation parameters are associated with poor prognosis in patients with novel coronavirus pneumonia [published online ahead of print, 2020 Feb 19]. J Thromb Haemost. 2020. https://doi.org/10.1111/jth.14768. 
4. Han H, Yang L, Liu R, Liu F, Wu KL, Li J, et al. Prominent changes in blood coagulation of patients with SARS-CoV-2 infection. Clin Chem Lab Med. 2020. https://doi.org/10.1515/cclm-2020-0188.

5. Rotzinger DC, Beigelman-Aubry C, von Garnier C, Qanadli SD. Pulmonary embolism in patients with COVID-19: time to change the paradigm of computed tomography [published online ahead of print, 2020 Apr 11]. Thromb Res. 2020;190:58-9. https://doi.org/10. 1016/j.thromres.2020.04.011.

Publisher's note Springer Nature remains neutral with regard to jurisdictional claims in published maps and institutional affiliations. 